\title{
Semi-active control design for base isolated structures with switching damping coefficient of oil dampers
}

\author{
A. Fukukita ${ }^{1} \&$ M. Takahashi ${ }^{2}$ \\ ${ }^{1}$ Institute of Technology, Shimizu Corporation, Japan \\ ${ }^{2}$ Faculty of Science and Technology, Keio University, Japan
}

\begin{abstract}
In Japan, after the Hyogo-ken Nambu Earthquake in 1995, base-isolated structures spread rapidly. Now, there are about 2,800 base-isolated buildings (apartment complexes account for $45 \%$ and hospitals for $12 \%$ ) and about 4,300 base-isolated houses in Japan. Base-isolation technology was effective in the Tohoku Earthquake 2011, off the Pacific coast. This paper presents the methods behind semi-active control design for base-isolated structures with oil dampers whose damping coefficient can be set in two levels: applying two different damping coefficients based on the proposed control design. The damping coefficients of the oil dampers are different to each other. The control objective is the reduction of both the displacement of a base-isolated layer and absolute acceleration of a base-isolated building, which are trade-offs against each other. The layered neural network with the Genetic Algorithm (GA) is applied to the semi-active control design. Absolute acceleration of the building and displacement of the isolated layer are the input signals of the neural network, and the switching parameter for the damping coefficient is the output signal of the neural network. The GA is used to adjust the neural network parameters that decide the control performance. The target of the control design is specified to permit the displacement of the base-isolated layer to the upper limit and to restrain the increase of building acceleration. We study the control performance of the proposed control method using several kinds of earthquake motions in the computer simulation.
\end{abstract}

Keywords: semi-active control, base isolation, neural network, genetic algorithm, variable oil damper. 


\section{Introduction}

Base isolated structures, which have proven to be effective against major earthquakes since the 1995 Hyogo-ken Nambu Earthquake, have started to spread rapidly throughout Japan. As of the end of 2010, there are approximately 2,800 base isolated structures in this country, consisting of 1,244 apartment complexes (45\%), 324 hospitals (12\%), 292 high-rise buildings (10\%) and others. Base isolation has also been applied to 110 existing buildings for retrofitting. In addition, the number of houses with base isolation is assumed to be about 4,300 [1]. The structures were proven to be effective against seismic vibrations from the Tohoku Earthquake on March 11, 2011 [2, 3].

Such base isolated structures have clearance between their building structures and the ground of about $60 \mathrm{~cm}$ to accept the displacement of a damping device. Once an earthquake occurs, the damping device is activated within the clearance to reduce the response acceleration of the building to prevent furniture and fixtures indoors from falling over, as well as to control damage to the framework of the building.

As the displacement of the base isolated layer and the absolute acceleration are a trade-off relationship, more clearance would be necessary to reduce the acceleration. However, effective building areas would be reduced by having more clearance inside, and construction costs would increase on application of this method. Therefore, it is desirable to reduce the absolute acceleration of structures with minor displacement of base isolated layer as less feasible. In order to achieve this function, conventional base isolated structures are designed to control damping of the base isolated layer to reduce the maximum acceleration within the clearance specified for designed seismic motions.

This paper describes the Genetic Algorithm (GA)-based method to design the minimum and maximum values of damping coefficient of a variable oil damper with two types of settings, and the semi-active control system to switch its settings by the neutral network. The objective of this method is to reduce the maximum response acceleration of structures while controlling the maximum displacement of the base isolated layer below a target value against an earthquake motion designed related to seismic motions in different characteristics. For comparison, the displacement of base isolated layer applying the optimum damping (hereinafter, the optimum passive) and the response acceleration are presented by assuming earthquake motions in designing a structure. Then, the method proposed in this paper explains that it would be better to control the response acceleration while reducing displacement of base isolated layer against earthquake motions not specified in the design better than that of the optimum passive. 


\section{Seismic motion and base-isolated structure models}

\subsection{Seismic motion}

In this paper, the three types of waves, JMA Kobe, Tokai-Tonankai [5], and BCJ are applied to design the control system. These waves are also applied to design the maximum passive response. Thus, there are nine types of waves referred to in this paper for consideration, including the three waves and Kanto [4], Nankai [6], Tokai [7], El Centro, Taft, Hachinohe. Amongst them, the acceleration waveform of the three types of waves including JMA Kobe, Tokai-Tonankai and $\mathrm{BCJ}$, and the velocity response spectrum for $5 \%$ of damping are shown in figs. 1 and 2 , respectively. The list of the seismic waves for consideration is as shown in table 1 .

Table 1: $\quad$ List of earthquakes.

\begin{tabular}{|c|c|}
\hline No. & Earthquake \\
\hline 1 & Kanto [4] \\
\hline 2 & Tokai-Tonankai [5] \\
\hline 3 & Nankai [6] \\
\hline 4 & Tokai [7] \\
\hline 5 & BCJ \\
\hline 6 & JMA Kobe NS (1995) \\
\hline 7 & El Centro NS (1940) \\
\hline 8 & Taft EW (1952) \\
\hline 9 & Hachinohe NS (1968) \\
\hline
\end{tabular}

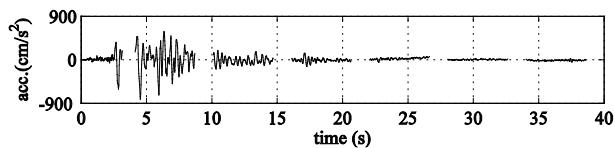

(a) JMA Kobe earthquake

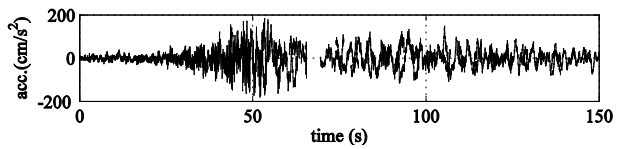

(b) Tokai-Tonankai earthquake
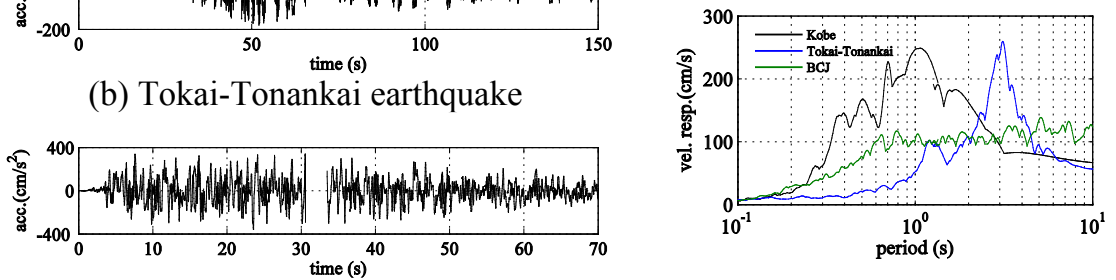

(c) BCJ earthquake

Figure 1: Seismic motion.

Figure 2: Response spectrum. 


\subsection{Base isolated structure models}

A 4-story base isolated structure went through analysis in this study, as shown in fig. 3, which has natural rubber isolators and the oil dampers with two levels of settings for a damping coefficient at the bottom. The seismic layer is designed to be linear, with a natural period of 3.9 seconds and $2 \%$ of damping constant at a state without the oil dampers as the superstructure is considered to be a one mass system. The superstructure is a linear type of equivalent shear model, and the damping factor is designed to be $2 \%$ as an internal viscous damping of the structure against the primary natural period only for the superstructure. Table 2 shows various constants of the base isolated structures.

Table 2: $\quad$ Specification of 4-degrees-of-freedom structural model.

\begin{tabular}{|c|c|c|c|}
\hline Layer & $\begin{array}{c}\text { Mass } \\
\left(\times 10^{3} \mathrm{~kg}\right)\end{array}$ & $\begin{array}{c}\text { Spring constant } \\
\left(\times 10^{8} \mathrm{~N} / \mathrm{m}\right)\end{array}$ & $\begin{array}{l}\text { Coefficient of } \\
\text { viscous } \\
\left(\times 10^{6} \mathrm{Ns} / \mathrm{m}\right)\end{array}$ \\
\hline 4 & 1000 & 1.2317 & 0.7841 \\
\hline 3 & 1000 & 1.8475 & 1.1764 \\
\hline 2 & 1000 & 2.4633 & 1.5681 \\
\hline 1 & 1000 & 0.1755 & 0.3351 \\
\hline Oil damper & - & 0.2940 & $\begin{array}{c}c_{s \min }=0.25 \sim 2.5(\mathrm{~min}) \\
c_{s \max }=2.5 \sim 25(\max )\end{array}$ \\
\hline
\end{tabular}

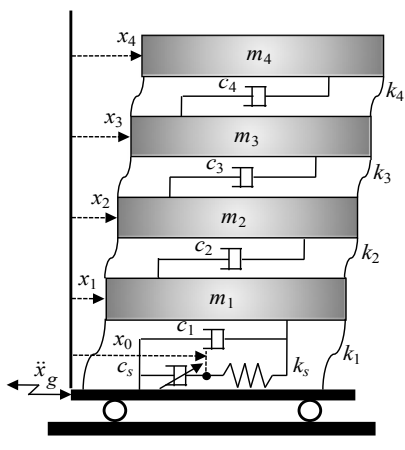

Figure 3: Structural model.

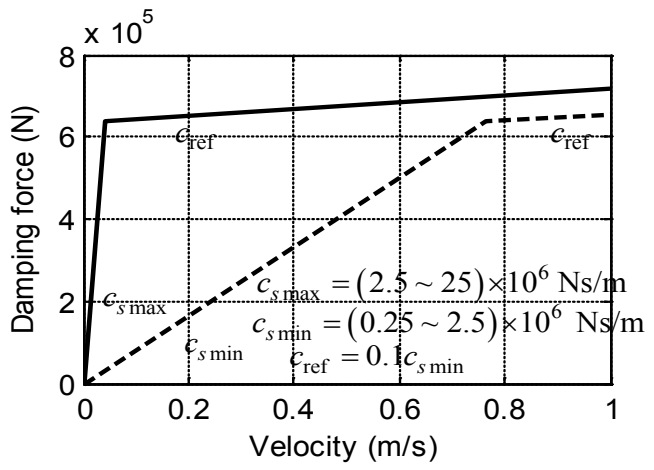

Figure 4: Characteristics of variable oil damper.

Oil dampers used in this study have a setting to change the levels of the damping coefficient as the maximum and minimum values by adjusting the degree of the opening of the valve as shown in fig. 4. The system is designed to relieve damping forces at about $640 \mathrm{kN}$. It is a Maxwell model connecting 
springs and dashpots in series. The specifications of the oil damper are as shown in table 2. Time-lag models are developed with the first-order lag element when changing the damping coefficient levels as shown in the following equation, as a response of an effective value to a command value.

$$
G_{d}(s)=\frac{1}{T s+1}
$$

Note that the time constant is specified as $T=30 \mathrm{msec}$ [8]. The structure has four oil dampers with the characteristics as above.

\subsection{Equation of motion and state space equation}

The following show the equations of motion of the base isolated structures as shown in fig. 3 .

$$
\begin{gathered}
c_{s}(t) \dot{x}_{0}(t)-k_{s}\left(x_{1}(t)-x_{0}(t)\right)=0 \\
m_{1}\left(\ddot{x}_{1}(t)+\ddot{x}_{g}(t)\right)+\left(c_{1}+c_{2}\right) \dot{x}_{1}(t)+\left(k_{s}+k_{1}+k_{2}\right) x_{1}(t) \\
-c_{2} \dot{x}_{2}(t)-k_{s} x_{0}(t)-k_{2} x_{2}(t)=0 \\
m_{i}\left(\ddot{x}_{i}(t)+\ddot{x}_{g}(t)\right)+\left(c_{i}+c_{i+1}\right) \dot{x}_{i}(t)+\left(k_{i}+k_{i+1}\right) x_{i}(t) \\
-c_{i+1} \dot{x}_{i+1}(t)-k_{i} x_{i-1}(t)-k_{i+1} x_{i+1}(t)=0 \quad(i=2,3) \\
m_{4}\left(\ddot{x}_{4}(t)+\ddot{x}_{g}(t)\right)+c_{4} \dot{x}_{4}(t)+k_{4} x_{4}(t)-c_{4} \dot{x}_{3}(t)-k_{4} x_{3}(t)=0
\end{gathered}
$$

Here, $m_{i}, c_{i}, k_{i}$ refer to the mass, damping coefficient and spring constant of each layer of the building, respectively. $c_{s}(t), k_{s}$ are for damping coefficient and spring constant for the Maxwell model. $\ddot{x}_{g}(t)$ refers to ground accelerations.

As for the state of quantity, considering oil damper's axis displacement $x_{0}(t)$ under the Maxwell model, relative displacement from the ground to each layer $x_{i}(t)$, and relative velocity $\dot{x}_{i}(t)$, the above equation of motion is described as equations of the state below:

$$
\begin{aligned}
& \dot{\boldsymbol{x}}_{\boldsymbol{s}}(t)=\boldsymbol{A}_{\boldsymbol{s}} \boldsymbol{x}_{\boldsymbol{s}}(t)+\boldsymbol{B}_{\boldsymbol{s}}\left\{x_{1}(t)-x_{0}(t)\right\} u(t)+\boldsymbol{D}_{\boldsymbol{s}} \ddot{x}_{g}(t) \\
& u(t)=\frac{1}{c_{s}(t)}
\end{aligned}
$$

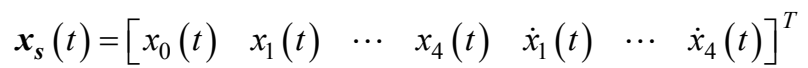

Accordingly, the structure model in this study is considered to be a bilinear system, as its unique feature is to have the term for a control input $u(t)$ being one of the functions of the quantities of state. 


\section{Control system design}

\subsection{Control objective}

The advantage that the semi-active control method presented in this paper can bring us is to achieve less displacement of base isolated layer than the optimum passive, and which even may reduce the response acceleration of buildings that is in a trade-off relationship, depending on earthquake motions. The following explains this in detail.

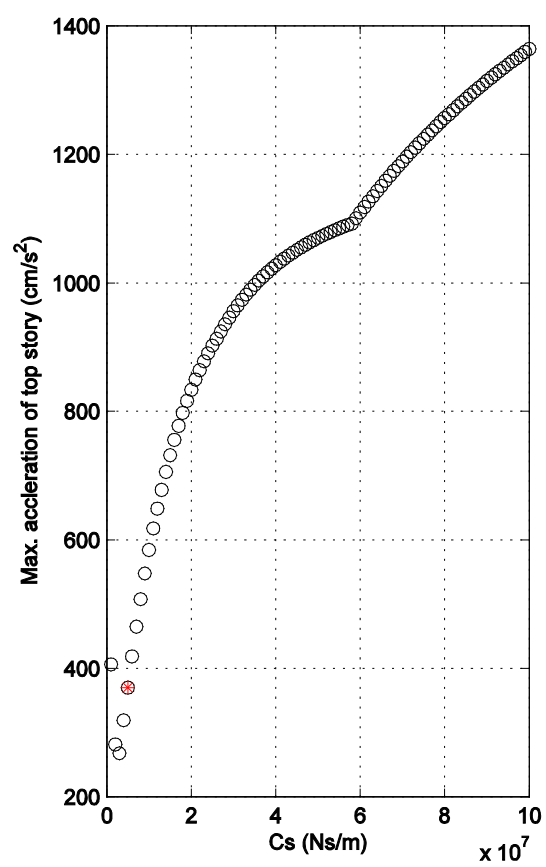

(a) Acceleration of top story

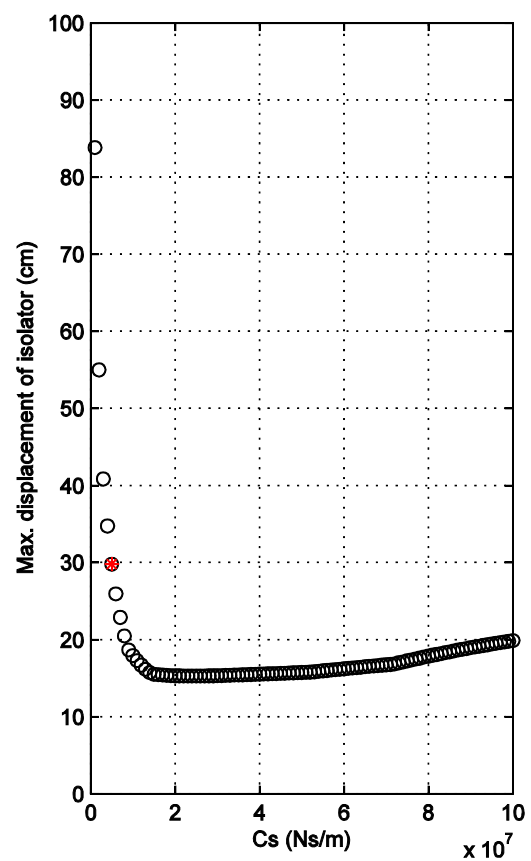

(b) Displacement of base isolation

Figure 5: Maximum response of the base-isolated structure of the three earthquakes for design to the damping coefficients.

Firstly, the optimum passive is defined. Among the nine types of earthquake motions as specified in 2.1, the three waves such as JMA Kobe, Tokai-Tonankai and BCJ are applied for calculation for the absolute acceleration of the displacement of base isolated layer and the top layer using damping coefficients in the range from $1.0 \times 10^{6} \mathrm{Ns} / \mathrm{m}$ to $100 \times 10^{6} \mathrm{Ns} / \mathrm{m}$. The results are as shown in fig. 5. Accordingly, we defined the optimum passive as a damping coefficient with the displacement of the base isolated layer is $30 \mathrm{~cm}$ or less, and the smallest absolute acceleration for the top layer, while identifying the maximum response value for the three waves. It leads the damping coefficient $c_{\text {sopt }}=5.0 \times 10^{6} \mathrm{Ns} / \mathrm{m}$ 
as shown in fig. 5 for the optimum passive which is indicated by the red mark. It should be noted that the JMA Kobe, Tokai-Tonankai and BCJ waves are selected as the input earthquake motions because these three waves have different values in the predominant period characteristics and time durations as shown in fig. 2, so that the results would be less deviated in designing the control systems. Thus, $\mathrm{BCJ}$ has earthquake motions not affecting response characteristics in designing a building because of its flat period characteristics. JMA Kobe and TokaiTonankai have earthquake motions with short-period pulses as one of the kind representing near-field earthquakes, and a long-period-type earthquake, respectively. It is considered that a robust control system can be designed against earthquake motions in various characteristics by using these three waves.

Next, we present some cases that were proven to reduce both the displacement of base isolated layer and the absolute acceleration of the top layer, compared to the optimum passive, by conducting the semi-active control to switch the damping coefficient into two modes. How to change the damping coefficient modes are described in the following.

\subsection{Multi-layered neural network}

This study proposes a method to design the minimum $\left(c_{s \min }\right)$ and maximum values $\left(c_{s \max }\right)$ of the damping coefficient for a variable oil damper located the base isolated layer. The control system is comprised of neural networks. Its control performance, which depends on a connecting weight and threshold value, is adjusted to be consistent with the valuation function.

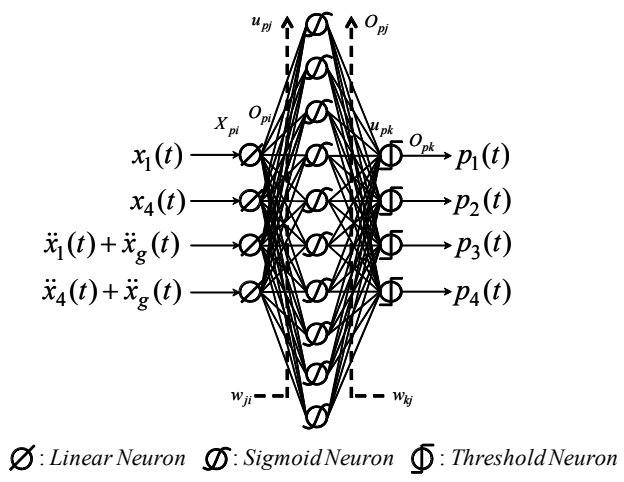

Figure 6: $\quad$ Multilayer neural network.

The control system with the two modes of the damping coefficient has a multi-layered neural network with the three layers including the input, hidden and output layers as shown in fig. 6. Four units of the system are provided, including the input layer with the four units including the displacement of base isolated layer, the story drift of the top layer, the absolute acceleration above the base isolated layer and the absolute acceleration of the top layer. The hidden 
layer has 10 units. The output layer has four oil dampers with the same performance to change its mode separately. The two-level mode setting referred to herein is not to change the two predetermined different values but to identify a reasonable value for both the minimum $\left(c_{s \min }\right)$ and maximum values $\left(c_{s \max }\right)$ of the damping coefficient to reduce the response as a mean. To identify these values, the GA is used as one of the optimization methods. Note that the range of $c_{s \min }$ and $c_{s \max }$ is specified as $c_{s \min }=0.25 \times 10^{6} \sim 2.5 \times 10^{6} \mathrm{Ns} / \mathrm{m}$, $c_{s \max }=2.5 \times 10^{6} \sim 25 \times 10^{6} \mathrm{Ns} / \mathrm{m}$. The calculations of each layer are as shown in eqns (9)-(15).

Input layer:

$$
O_{p i}=X_{p i}, \quad i=1, \quad 2, \quad \cdots, \quad n_{i}
$$

Hidden layer:

$$
\begin{gathered}
u_{p j}=\sum_{i=1}^{n_{i}} w_{j i} O_{p i}+\theta_{j}, \quad j=1, \quad 2, \quad \cdots, \quad n_{j} \\
O_{p j}=f_{h}\left(u_{p j}\right)
\end{gathered}
$$

Output layer:

$$
\begin{gathered}
u_{p k}=\sum_{j=1}^{n_{j}} w_{k j} O_{p j}+\theta_{k}, \quad k=1, \quad 2, \quad \cdots, \quad n_{k} \\
O_{p k}=f_{o}\left(u_{p k}\right)
\end{gathered}
$$

Transfer function (input layer --> hidden layer):

$$
f_{h}(x)=\frac{2}{1+\exp (-2 x)}-1
$$

Transfer function (hidden layer --> output layer):

$$
f_{o}(x)= \begin{cases}1 & (x \geq 0) \\ 0 & (x<0)\end{cases}
$$

where, $w$ and $\theta$ are connecting weight and threshold value, respectively. As the data for the input layer, the displacement of base isolated layer is $30 \mathrm{~cm}$ for the response value in case of the optimum passive and the absolute acceleration as one normalized at the response value of approximately $400 \mathrm{~cm} / \mathrm{s}^{2}$ for the top layer for the optimum passive.

\subsection{Learning procedure}

For calculating a seismic response, it hardly presumes the behaviors even when controlling a damping device for the structure; it is difficult to present explicit lessons to adjust parameters of the connecting weight $w$ and threshold value $\theta$ for the multi-layered neural network. Therefore, the GA is applied in this study as one of the representing optimization methods to determine the connecting 
weight $w$ and threshold value $\theta$ as below so as to achieve consistency with the predetermined evaluation function.

There are 18 chromosomes provided containing the codes of both the minimum $\left(c_{s \min }\right)$ and maximum values $\left(c_{s \max }\right)$ of the damping coefficient of the variable oil damper installed at the base isolated layer, considering connecting weight $w$ and threshold value $\theta$ between layers. Then, the following evaluation function $f$ shown below is applied to calculate the fitness for the individual:

$$
f_{a}=\frac{f=1000 p_{x} f_{a}}{\exp \left(\frac{a^{\max }-a_{\text {min }}}{a_{\text {min }}}\right)}
$$

where, $p_{x}, f_{a}, a^{\max }$ and $a_{\min }$ are the penalty function for the displacement of base isolated layer, the evaluation function of the absolute acceleration of the top layer, the absolute acceleration of the top layer and the target absolute acceleration of the top layer, respectively. The penalty function $p_{x}$ is calculated as below, to have a lower evaluation when it exceeds the displacement of base isolated layer at the optimum passive.

$$
p_{x}= \begin{cases}1.0 & \left(x^{\max }<x_{p_{\text {opt }}}\right) \\ 0.01 & \left(x^{\max }>x_{p_{\text {opt }}}\right)\end{cases}
$$

where, $x^{\max }$ is the maximum value of the displacement of base isolated layer. $x_{p_{\text {opt }}}$ is the displacement of base isolated layer at the optimum passive.

The equations above are applied to calculate the fitness of the 18 individuals to identify two from an elite preservation strategy, four from a roulette strategy and one as the parent of next generations. These parents are paired to generate four individuals through a uniform crossover and mutation. This process, which is considered as one generation, is repeated multiple times to find an individual with higher fitness.

Assuming the output from a multi-layered neural network as $p(t)$, a damping coefficient $c_{S}(t)$ for the damper is determined as the following equation, as $p(t)$ outputs 0 or 1 :

$$
\begin{gathered}
c_{s}(t)=(1-p(t)) c_{s \max }+p(t) c_{s \min } \\
p(t)=0 \text { or } 1
\end{gathered}
$$

where $c_{s \min }$ and $c_{s \max }$ are the minimum and maximum values of the damping coefficients of the oil damper, respectively. Therefore, eqns (19) and (20) are to select either the minimum and maximum value as a damping coefficient of the damper. 
The authors conducted the study for the near-field earthquake of the JMA Kobe wave, Tokai-Tonankai waves (Chubu wave) as a long cyclical period, and the BCJ wave in order to design the control system.

\section{Simulation}

The nine seismic waves presented in 2.1 are applied to the base isolated structure model in fig. 3 using the control system designed in Chapter 3 to lead the response acceleration of the top layer and the displacement of base isolated layer. The results are shown in fig. 7 . Fig. 7 (b) shows that the displacement of base isolated layer is lower than the optimum passive response for all the seismic waves (except Kanto (No. 1)) including Tokai-Tonankai (No. 2), BCJ (No. 5), JMA Kobe (No. 6) applied to the control system design. Furthermore, the absolute acceleration of the top layer for JMA Kobe (No. 6) and El Centro (No. 7) are lower than the optimum passive response, which means that both displacement of base isolated layer and the absolute acceleration of the top layer could be reduced below the target level of the optimum passive response. The seismic waves, other than those of JMA Kobe (No. 6) and El Centro (No. 7), show an increase of the absolute acceleration of the top layer when the displacement of base isolated layer is reduced. However, the value remains below the optimum passive value of JMA Kobe (No. 6), which is the largest among all the seismic waves, and meets the target value of the semi-active control.

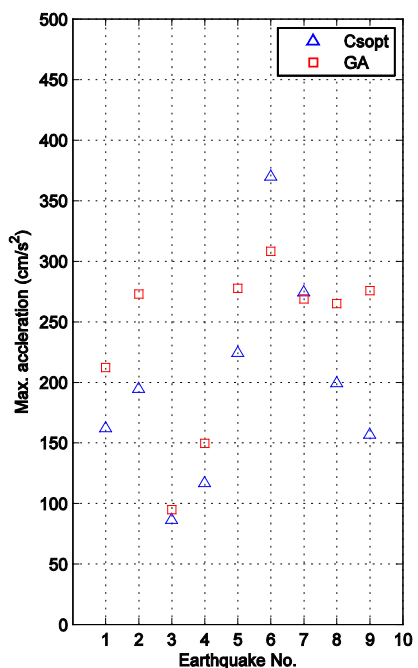

(a) Acceleration of the top story

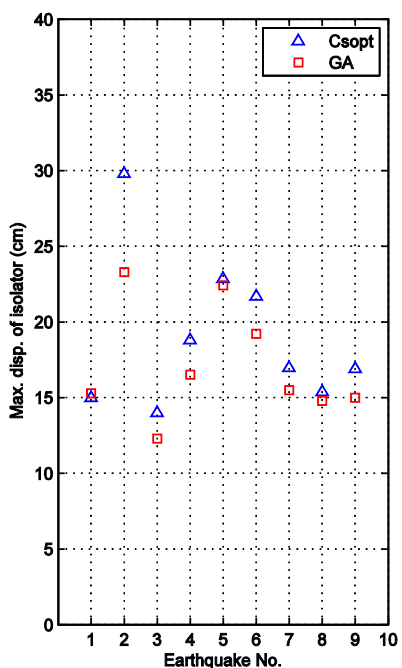

(b) Displacement of base isolation

Figure 7: Maximum response of the base-isolated structures of the nine earthquakes to the damping coefficients. 

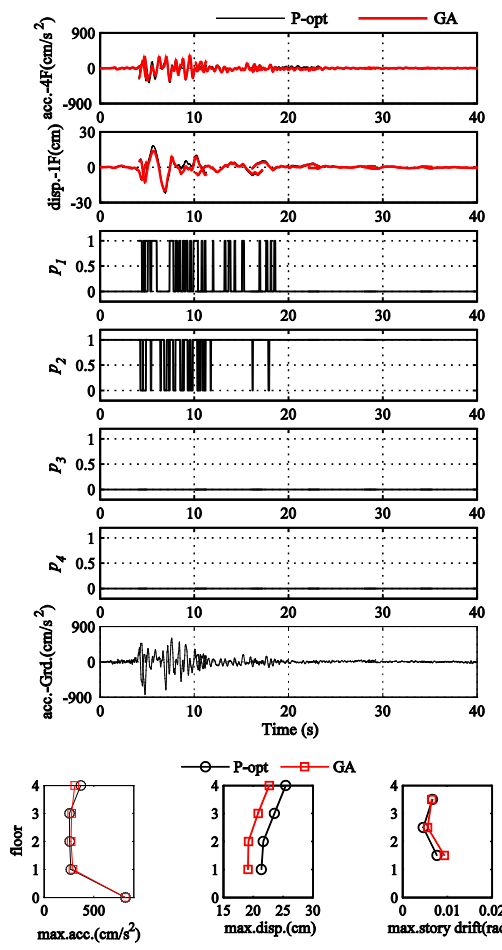

(a) JMA Kobe (No. 6, learned)
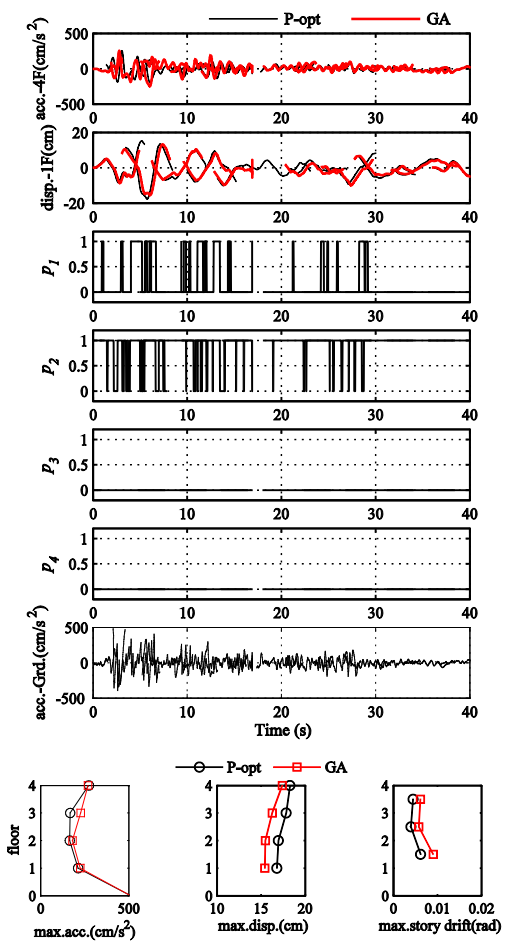

(b) El Centro (No. 7, not learned)

Figure 8: $\quad$ Response of the base-isolated structure.

Fig. 8 shows the waveforms for time histories for JMA Kobe, which are used for the control system design, while those for the El Centro are not. The figure shows $p_{i}(t)$ as a change of switching signal for the damping coefficients. The timing varies depending on $p_{1}(t)$ and $p_{2}(t)$, which implies that the output signal shown in fig. 6 is as intended. The response reduced more than that of the optimum passive value for both absolute acceleration of the top layer and the displacement of base isolated layer for JMA Kobe, which is used for the control system design. It refers to a characteristic of the semi-active control. As the El Centro, which is not used for the control system design, shows a similar tendency to that of JMA Kobe, the semi-active control proves a certain level of robustness in the design.

\section{Conclusion}

This paper presents a method to design a semi-active control system using the GA. The semi-active control system changes its modes using the minimum and maximum values of the damping coefficient of the variable oil damper located at 
the base-isolation layer with two levels of settings and a neural network, which aims to reduce the maximum response acceleration of a building while keeping the maximum displacement of its base-isolation layer below the target value of earthquakes in the different scales assumed when designing the structure. It reveals that the proposed semi-active control system is also efficient in keeping the response acceleration low while reducing the displacement of base-isolation layer against earthquakes that were even unexpected when designing the structure, against the response of a base-isolation structure of the optimum passive value.

\section{References}

[1] The Japan Society of Seismic Isolation: http://www.jssi.or.jp/menshin/ doc/ms_ss_data.pdf

[2] Shimizu Corporation website, The Great Tohoku Earthquake related technical report - effects of base isolated structures. See also URL http://www.shimz.co.jp/theme/earthquake/effect.html

[3] Saruta, M., Okada, K., Nakamura, Y., and Hasebe, M., The 2011 off the Pacific Coast of Tohoku Earthquake and Response of Base Isoalted Structures. Summaries of Technical Papers of Annual Meeting Architectural Institute of Japan, B-2:Structures II, pp. 629-630, 2011.

[4] Sato, T., and Dan, K., Wide band strong motion prediction of areas around Tokyo by using the Kanto earthquake. Recommendation for the Design of Base Isolated Buildings, Architectural Institute of Japan, pp. 263-274, 2001.

[5] The Ministry of Land, Transport and Infrastructure Organization Chart of Chubu Regional Development Bureau and Consortium, Basic Seismic Motion Data for Seismic Reinforcement of Buildings in Sannomaru, Nagoya City considering Regional Characteristics (Summary), p.48, 2004.

[6] Kamae, K., Kawabe, H. and Irikura, K, "Strong Ground Motion Prediction for Huge Subduction Earthquakes Using a Characterized Source Model and Several Simulation Techniques", 13th World Conference on Earthquake Engineering, Paper No.655, 2004.

[7] Hijikata, K., Uetake, T., Kanaya, J., Mashimo, M., Hayakawa, T., Watanabe, M., and Sato, T., Quantitative Prediction of Long-period Ground Motions of Tokyo Bay Area From the Tokai Earthquake, Journal of Strucutural and Construction Engineering, Architectural Institute of Japan, 617, pp. 55-62, 2007.

[8] Yoshida, K., and Fujio, T., Bilinear Optimal Control Theory and its Application to Semi-Active Vibration Isolation Control. Transactions of the Japan Society of Mechanical Engineers, Series C, 67:656, pp. 992-998, 2001 . 